\title{
Emission prediction model for a multidisciplinary assessment framework
}

\author{
Siti Nur Mariani Mohd Yunos, Mohammad Fahmi Abdul Ghafir and Abas Ab Wahab
}

\begin{abstract}
This paper presents the work conducted as part of an effort in developing a multidisciplinary assessment framework for trade off study between technical, economic and environmental aspects of alternative jet fuels application specifically in commercial aircraft. At present, empirical prediction method has been explored so as to be the basis in predicting the amount of emissions that have a huge influence towards the environment. An emission prediction model based on Boeing Fuel Flow Method 2 (BFFM2) has been adopted and its accuracy and applicability has been tested on a specified engine model. The model was then used to evaluate and to compare the amount of emission emitted due to the combustion of alternative fuels, namely Camelina- and Jatropha- synthetic paraffinic kerosene (SPK) with the conventional jet fuel, Jet A. With emphasis on emissions of nitrogen oxides (NOx) and carbon monoxide (CO) at take-off and cruise conditions, the results indicate that the alternative fuels managed to reduce NOx emissions up to 3 percent but at an expense of increasing amounts of $\mathrm{CO}$. The effects of alternative fuels usage compared to Jet A towards the amount of emissions as well as engine performance are also discussed in the paper. Overall, the model has proven acceptable to be incorporated within an assessment framework for a thorough evaluation of aviation alternative jet fuel to reduce dependency on the conventional fossil fuel.
\end{abstract}

Keywords - engine performance, aviation emissions, nitrogen oxides, carbon monoxide, drop-in fuel, BFFM2

\section{Introduction}

The demand for air travel is highly associated with the enhancement in safety, reliability, efficiency and comfort of its operation [1]. With an anticipated growth at 5\% per year for the next 20 years [2], air travel has caused a significant concern as it is associated primarily with increasing fossil fuel demand, pollutant emissions and noise which in return will also affect the industry operating costs. Fluctuations in fuel price have a direct influence towards airlines costs and profits. On the other hand, aircraft engine exhaust emissions such as

Siti Nur Mariani Mohd Yunos

Fac. of Mechanical \& Manufacturing Engineering, Universiti Tun Hussein Onn Malaysia, 86400 Parit Raja, Johor, Malaysia.

Mohammad Fahmi Abdul Ghafir

Fac. of Mechanical \& Manufacturing Engineering, Universiti Tun Hussein Onn Malaysia, 86400 Parit Raja, Johor, Malaysia.

Abas Ab Wahab

Fac. of Mechanical \& Manufacturing Engineering, Universiti Tun Hussein Onn Malaysia, 86400 Parit Raja, Johor, Malaysia. nitrogen oxides $\left(\mathrm{NO}_{\mathrm{X}}\right)$ and carbon dioxides $\left(\mathrm{CO}_{2}\right)$ are identified to have a notable impact towards climate change. In order to reduce these drawbacks, various technological and operational solutions have been suggested. Ambitious targets have been set and translated into International Air Transport Association's four-pillar strategy comprising technology, operations, infrastructures and economic measures [3]. Among the targets are to further reduce $\mathrm{CO} 2$ emissions by $50 \%$ by 2050 and improve the fuel efficiency by $1.5 \%$ annually up until 2020. Meanwhile, the range of solutions for improving aircraft and engine designs is extensive. Although some of the solutions related to aircraft and engine improvements are feasible, they might take a long time and a huge investment before the technologies can become viable for the industry. Due to this reason, the application of alternative fuels, particularly drop-in fuel, on the aero gas turbine are considered to be good alternatives and key short term solutions. This solution has a potential to further reduce fossil fuel consumption and aviation's environmental impact without major aircraft modifications and adaptations.

Realizing the complexity of the assessments of their impact towards the environment and operating costs, critical considerations in terms of technological, economic and environmental aspects are required. Such assessments require a framework that could holistically assess the effect of alternative fuel application by considering the performance of the aircraft and its engine, operating costs and impact towards the environment. With this aspiration, an emission prediction model that can fit and assist in a multidisciplinary assessment framework has been proposed. This paper describes the approach taken in incorporating an empirical prediction method in the proposed model. It first starts with a description on the engine model performance and alternative fuel setup. The capability of the emission prediction model to estimate the amount of emission has been validated with an open literature. Furthermore, assessment on two types of alternative jet fuels and its comparison with the conventional fossil fuel were also reported.

\section{Method}

\section{A. Engine Performance Setup}

An engine model that replicates the performance of a CFM56-7B26 turbofan engine has been constructed using GasTurb in accordance with technical and performance specification data obtained from open literatures. GasTurb was used to simulate the engine performance at various operating conditions and fuels. Based on the available data, the design point has been chosen at sea level take-off (Alt $=0 \mathrm{~m}$, Mach $=$ $\left.0, \Delta \mathrm{T}_{\mathrm{ISA}}=0 \mathrm{~K}\right)$. The important design point parameters and the 
Proc. of the Third Intl. Conf. on Advances in Mechanical, Aeronautical and Production Techniques - MAPT 2015

Copyright $(\subseteq$ Institute of Research Engineers and Doctors, USA .All rights reserved.

ISBN: 978-1-63248-059-0 doi: 10.15224/ 978-1-63248-059-0-68

comparison of performance between the simulated model and publicly available data are given in Table I.

TABLE I. DESIGN POINT SPECIFICATIONS AND PERFormance

\begin{tabular}{|l|c|c|c|}
\hline $\begin{array}{c}\text { Design and } \\
\text { Performance } \\
\text { Parameters }\end{array}$ & $\begin{array}{c}\text { Simulated } \\
\text { model }\end{array}$ & $\begin{array}{c}\text { Public } \\
\text { Literature }\end{array}$ & $\begin{array}{c}\% \\
\text { Difference }\end{array}$ \\
\hline Engine mass flow $[\mathrm{kg} / \mathrm{s}]$ & 353.348 & 353.348 & 0 \\
\hline Outer fan pressure ratio & 1.768 & - & - \\
\hline Overall pressure ratio & 27.61 & 27.61 & 0 \\
\hline Bypass ratio & 5.1 & 5.1 & 0 \\
\hline TET $[\mathrm{K}]$ & 1617.44 & - & - \\
\hline Fuel flow $[\mathrm{kg} / \mathrm{s}]$ & 1.221 & 1.221 & 0 \\
\hline Thrust $[\mathrm{kN}]$ & 116.0 & 116.99 & 0.85 \\
\hline SFC $[\mathrm{g} / \mathrm{kN}-\mathrm{s}]$ & 10.8 & 10.5259 & 2.6 \\
\hline
\end{tabular}

An approach explained by [4] has been applied to model the engine. As the outer fan pressure ratio is unavailable, it was adapted to the ideal jet velocity ratio, which is given as a product of low pressure turbine efficiency and fan efficiency. Meanwhile, turbine entry temperature (TET) was iterated to achieve the reported fuel flow value. The compressor pressure ratios were adapted to the overall pressure ratio, while the isentropic efficiency of fan, compressors and turbines were adapted to achieve the targeted performance. These steps were carried out to ensure that the engine model performance simulation is accurate at the design point.

\section{B. Alternative Fuel Setup}

A drop-in jet fuel such as bio-synthetic paraffinic kerosene (bio-SPK) type of fuel has been specifically selected in the study due to its potential to replace the conventional fuel (Jet A) either in full or blend ratios without modification to existing aircraft/engine infrastructure [5].

Gas property data of two potential bio-SPK fuels from Camelina and Jatropha as reported by [6] has been prepared using NASA CEA and defined in the GasTurb. The composition of each fuel as well as its heat of formation have been utilized in preparing the data. A comparison between these fuels and Jet A is given in Table II. It is worthwhile to note that blend ratios are not demonstrated at this stage of study, hence the result only reflects the application of $100 \%$ Camelina-SPK and Jatropha-SPK.

TABLE II. FUEL COMPARISONS

\begin{tabular}{|l|c|c|c|}
\hline \multicolumn{1}{|c|}{ Parameters } & Jet A & $\begin{array}{c}\text { Camelina } \\
\text { SPK }\end{array}$ & $\begin{array}{c}\text { Jatropha } \\
\text { SPK }\end{array}$ \\
\hline Molecular formula & $\mathrm{C}_{12} \mathrm{H}_{23}$ & $\mathrm{C}_{12} \mathrm{H}_{25.4}$ & $\mathrm{C}_{12} \mathrm{H}_{26}$ \\
\hline Heat of combustion $[\mathrm{MJ} / \mathrm{kg}]$ & 43.1 & 44.0 & 44.3 \\
\hline
\end{tabular}

\section{Emission Prediction}

Several methods for predicting the amount of aircraft emissions are available and have been discussed comprehensively by [7]. Amongst the available prediction models, the empirical model tends to be the least computationally extensive. The model can be implemented either by using engine thermodynamic parameters or using the fuel flow during landing and take-off (LTO) operations defined by ICAO. The latter was developed and derived from the P3-T3 method which entails engine proprietary information for its estimation.

In this study, Boeing Fuel Flow Method 2 (BFFM2) [8] has been used in estimating engine emissions due to its

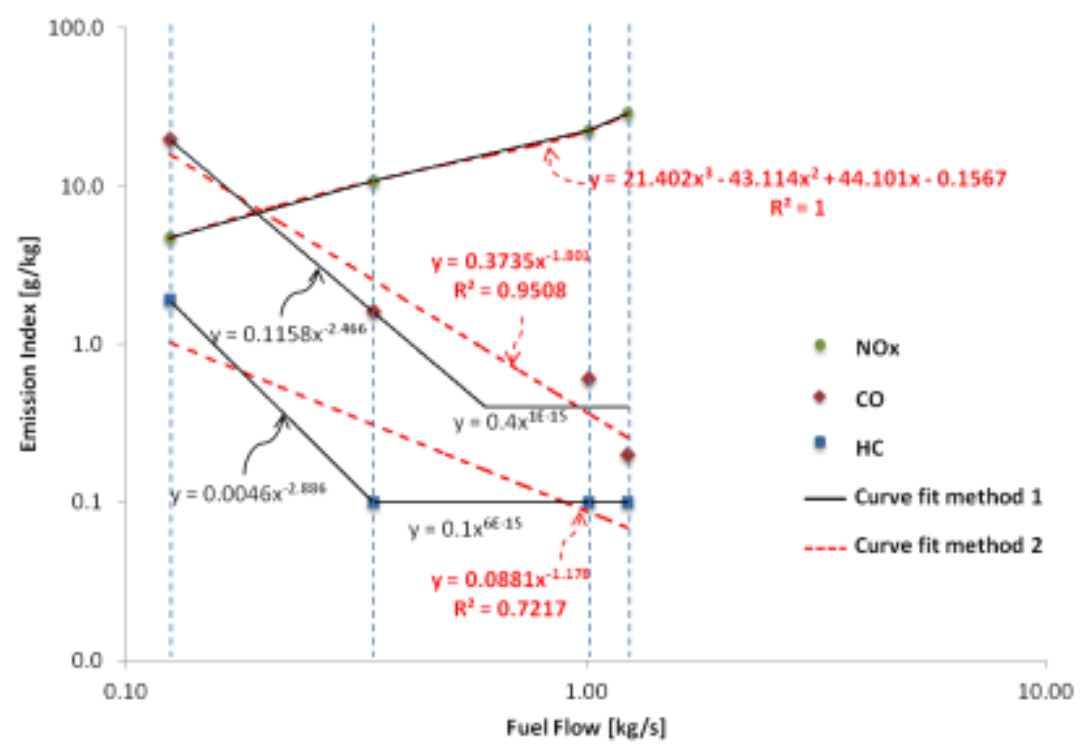

Figure 1. Logarithmic plot of engine model's ICAO data points 
inexpensive computational time and simplicity. Earlier, this method has been widely used in a number of studies as it has lifted the dependency on proprietary data which is not always publicly available [9]-[13].

Data from ICAO Aircraft Engine Emission Databank have been used to plot the log-log graph of emission indices (EI) against fuel flow. The databank offers comprehensive database of jet engine emissions certification data provided by engine manufacturers that covers the emissions of $\mathrm{CO}, \mathrm{NO}_{\mathrm{x}}$ and $\mathrm{HC}$ and maximum smoke number from turbojet and turbofan aircraft engine [14]. Each emission is represented by an emission index (EI) at a corresponding fuel flow rate and respective power setting. Reference values for $\mathrm{CO}, \mathrm{NOx}$ and $\mathrm{HC}$ of CFM56-7B26 are given in Table III.

TABLE III. ICAO DATA FOR CFM56-7B26

\begin{tabular}{|l|c|c|c|c|c|}
\hline \multicolumn{1}{|c|}{ Mode } & $\begin{array}{c}\text { Power } \\
\text { setting } \\
{[\% \mathbf{F}]}\end{array}$ & $\begin{array}{c}\text { Fuel } \\
\text { Flow } \\
{[\mathbf{k g} / \mathbf{s}]}\end{array}$ & CO & NOx & HC \\
\hline Take off & 100 & 1.221 & 0.2 & 28.8 & 0.1 \\
\hline Climb & 85 & 0.999 & 0.6 & 22.5 & 0.1 \\
\hline Approach & 30 & 0.338 & 1.6 & 10.8 & 0.1 \\
\hline Idle & 7 & 0.113 & 19.8 & 4.7 & 1.9 \\
\hline
\end{tabular}

To account for the engine installation effect on an airframe, BFFM2 has introduced an installation correction factor (IEF) for the reported fuel flow at each power setting $(100 \%=1.01,85 \%=1.013,30 \%=1.02,7 \%=1.1)$. The corrected fuel flow was then plotted together with the value of emission as shown in Figure 1. An empirical relation is generated by finding the best curve fit for each plot.

Note that in this study, the engine performance has been modeled without taking into account the installation effect. Hence, the fuel flow from the engine simulation was corrected by applying a factor determined based on the installation correction factor of the four power settings. The correction factors are determined according to the following conditions:

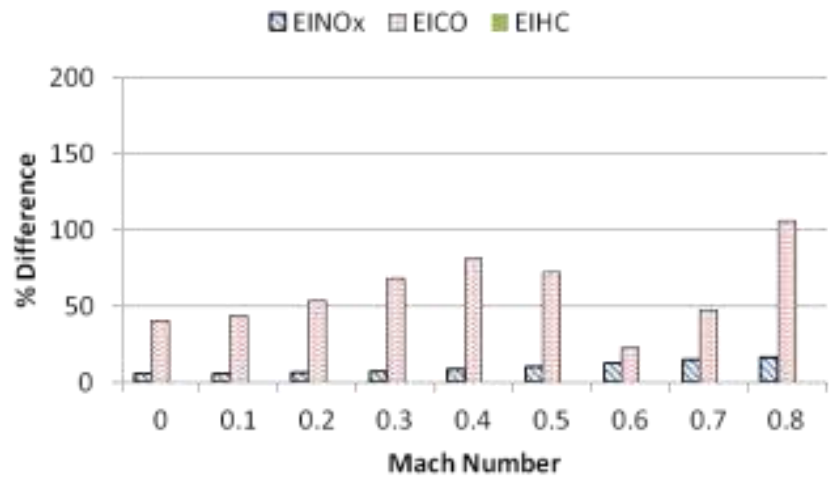

(a)
For fuel flow $\leq 0.338 \mathrm{~kg} / \mathrm{s}$ :

$$
I E F=-0.3556 \dot{m}_{f}+1.1402
$$

For fuel flow $>0.338 \mathrm{~kg} / \mathrm{s}$ :

$$
I E F=-0.003556 \dot{m}_{f}^{2}-0.0062 \dot{m}_{f}+1.0225
$$

An equivalent fuel flow at sea level was calculated using the corrected fuel flow. Consequently, the equivalent emission index at sea level for each pollutant was found through correlations that present the curve fits. Emission estimation was then completed by applying a pressure correction factor using the procedures outlined by BFFM2.

\section{Validation}

An empirical emission assessment model for the CFM567B engine family has been developed by [15] using ICAO emission data and actual flight data. A set of correlation that can be used to predict the engine emission based on the fuel flow at different flight phase has been established. Earlier in the previous subsection, two curve fits have been presented in Figure 1. The first method represents a bilinear and trilinear fits following a method explained in [8] while the second method represent a linear and polynomial fits for the three emissions. In order to find the best curve fit that presents the best behavior of each emission, the results of emission index of $\mathrm{CO}, \mathrm{NOx}$ and $\mathrm{HC}$ at sea level for each curve fit have been compared with results presented by [15]. As can be seen in Figure 2, results presented by curve fit method 1 for NOx and $\mathrm{HC}$ are in a close agreement with [15]. On the hand, curve fit method 2 can predict the emission of $\mathrm{CO}$ better than curve fit method 1. Hence, for the rest of this paper, curve fit method 1 was used to predict the emission index of NOx and HC while $\mathrm{CO}$ was presented by curve fit method 2 .

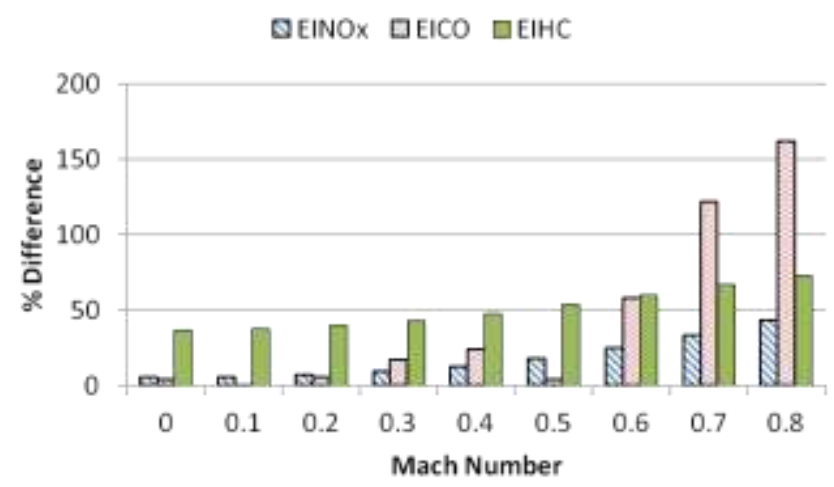

(b)

Figure 2. Percent difference between two curve fits: (a) curve fit method 1 and (b) curve fit method 2 with [15] 


\section{Results and Discussion}

\section{A. Effect of Alternative Fuels on Engine Performance}

In the presented method, fuel flow plays an important role in predicting the amount of emission produced by the engine. To understand the behavior of the fuel flow of different fuels at different flight operating conditions, the engine was simulated to run at take off and cruise with variation in TET and the results are given in Figure 3. As expected, with higher power requirements during take-off, fuel flow rate for all three fuels are relatively higher compared to cruise. It can also be observed that the fuel flow increased linearly with the increase in TET. In terms of the effect of different fuel usage towards fuel flow rate, Jatropha-SPK presents the lowest fuel flow, followed by Camelina-SPK and Jet A for both take-off and cruise conditions. The fuel flow of an engine running with Jatropha-SPK is reduced further at higher TET with an average of up to 2 percent difference with Jet A.

Additionally, to illustrate the effect of their usage towards engine performance, percent change of alternative fuels in relative to Jet $\mathrm{A}$ in terms of net thrust and fuel consumption are given in Figure 4 and Figure 5. More thrust is generated at take-off and lesser fuel is consumed at cruise condition compared to Jet A. With an average different of about 2.26 and 2.32 percent in fuel consumption at both operating conditions, Jatropha-SPK shows its capability in saving considerable amount of fuel without sacrificing the thrust produced by the engine. The thrust managed to be improved by up to 0.27 percent in average in relative to Jet A. Overall, with a higher heating value, Jatropha- and Camelina-SPK managed to further improve the engine performance, consistent with finding presented by [6].

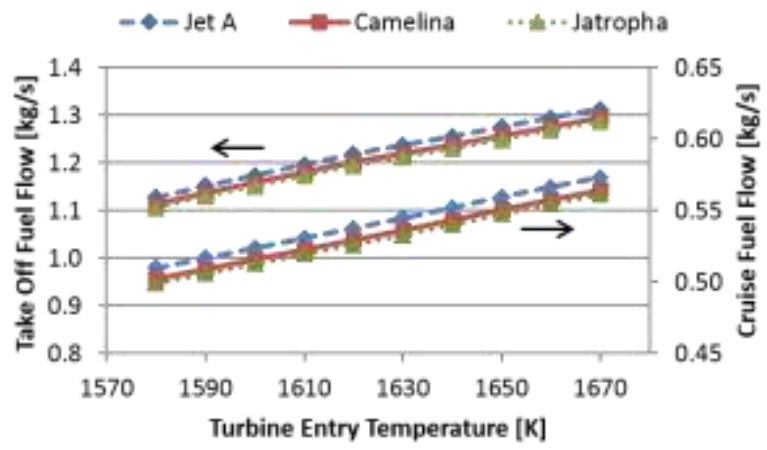

Figure 4. Variation of fuel flow for various fuels at take-off and cruise conditions

\section{B. Effect of Alternative Fuels Exhaust Emissions}

The application of both Camelina and Jatropha-SPK fuels at take-off and cruise conditions has been evaluated for their effects towards NOx and $\mathrm{CO}$ emissions. Figure 6 indicates the variation of EINOx, EICO and EIHC at take-off and cruise
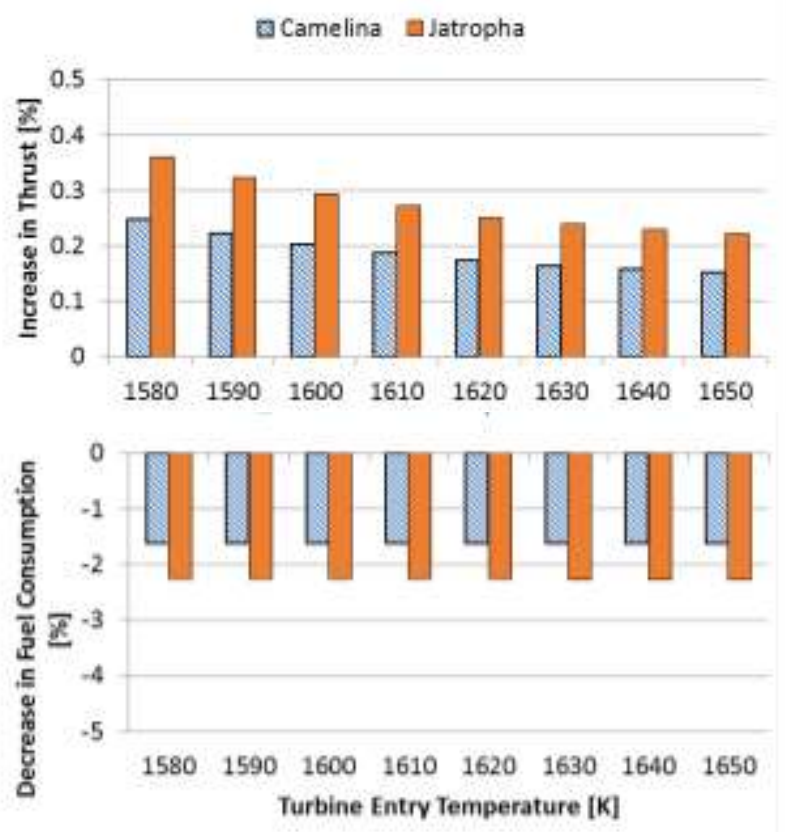

Figure 3. Increase in thrust and fuel consumption at take-off condition $($ Alt $=0 \mathrm{~m}$, Mach $=0)$
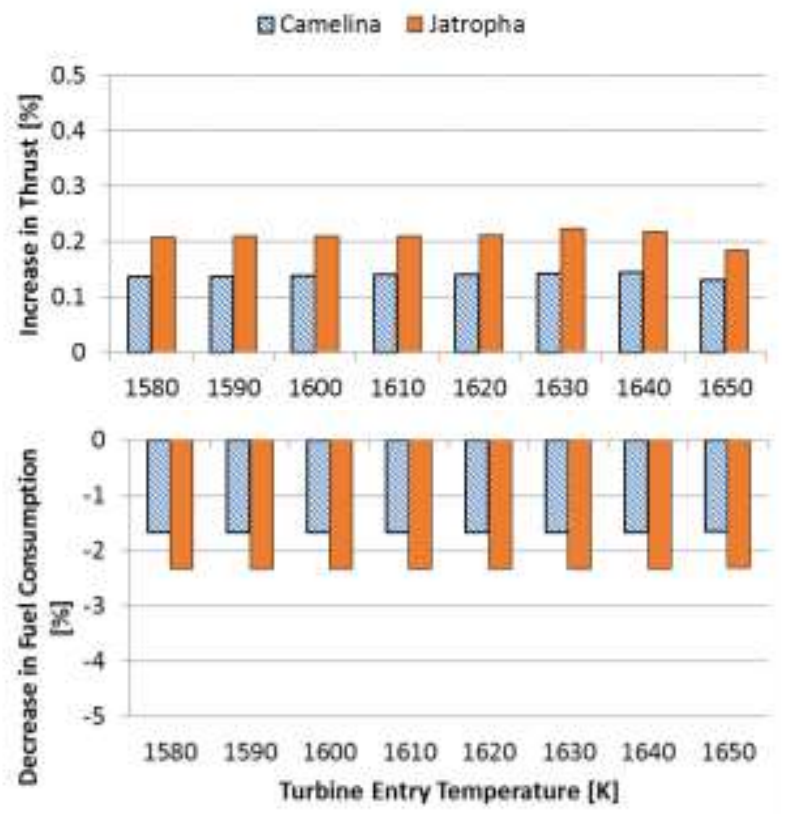

Figure 5. Increase in thrust and fuel consumption at cruise condition $($ Alt $=10668 \mathrm{~m}$, Mach $=0.8)$

with TET. The figures show that the Camelina and JatrophaSPK fuels managed to decrease NOx by up to 2 and 3 percent, respectively but at an expense of 3 and 4 percent increment in $\mathrm{CO}$ in relative to Jet A. Figure 6 also shows that the emission of NOx is significantly higher than $\mathrm{CO}$ at a take-off condition which explains its global significant concern on ground level aviation emission. Although the amount of $\mathrm{CO}$ is quite small compared to NOx, it is still crucial to further reduce its amount particularly at cruise or low power setting as it is found to be 
higher at this condition. It is indeed of significance that at sea level take-off, the value of EIHC remains fixed at $0.1 \mathrm{~g} / \mathrm{kg}$ of fuel as any increment in corrected fuel flow over $0.345 \mathrm{~kg} / \mathrm{s}$ has neither negative nor positive impact towards EIHC as indicated by curve fit method 1 in Figure 1 . As indicated in Figure 6, at higher altitude (e.g. cruise condition), pressure correction factor was applied for EIHC, hence a small increment in the emission indices.
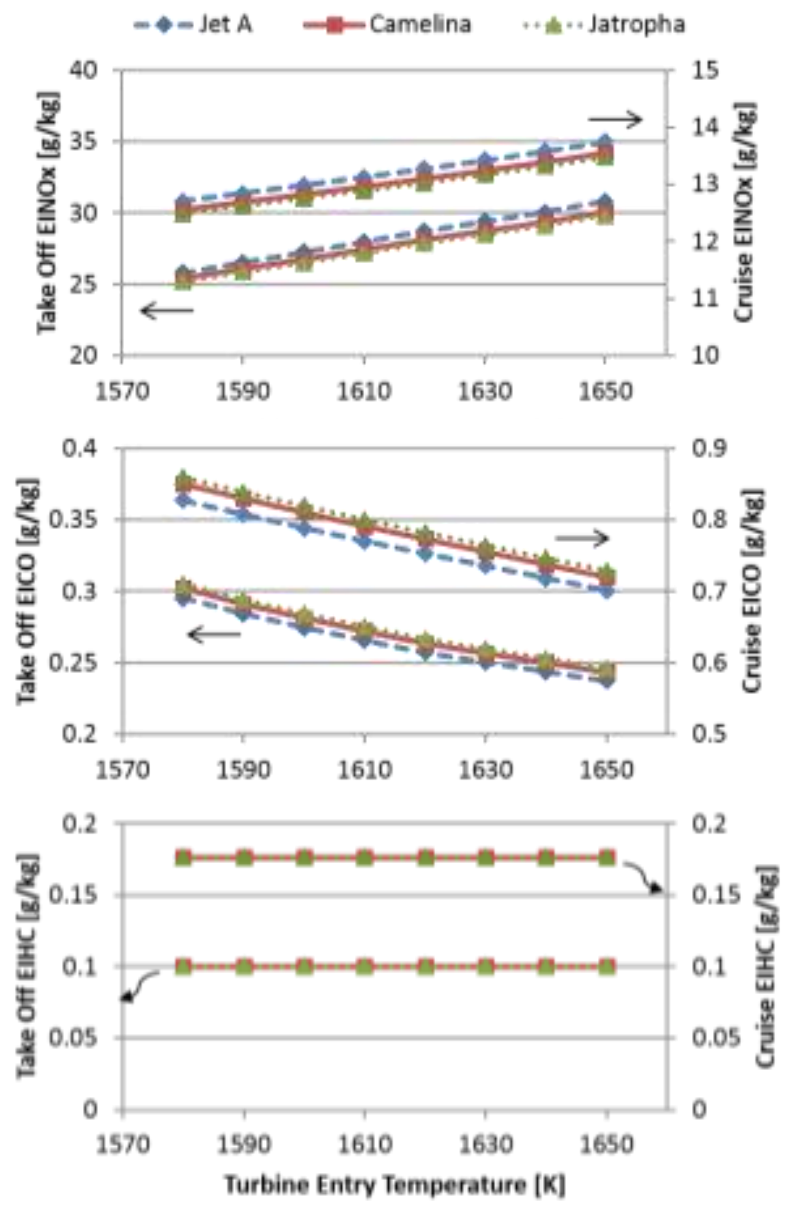

Figure 6. Variation of EINOx, EICO and EIHC of various fuels at takeoff and cruise conditions

\section{Conclusions}

This paper provides an application of the BFFM2 emission prediction method in predicting exhaust emissions of a specific turbofan engine for two alternative drop-in jet fuels as well as its validation with reported and established study. A comparison with a reported study shows an acceptable agreement with the predicted amount of emissions given the limited information on the respective engine. The result of the assessment of the application of the alternative fuels shows a notable improvement in engine performance. By focusing on the emissions of engine operation at sea level where the thrust setting and fuel flow are expected to be at their highest, the model shows that the engine emits higher NOx by running with Jet $\mathrm{A}$, but the amount of emission per $\mathrm{kg}$ fuel can be reduced by applying alternative fuels such as Jatropha- and
Camelina-SPK. It is worth to note that such application has a slight drawback at higher altitude at which fuel flow is lesser, as the emission of $\mathrm{CO}$ is noticeably higher. Further usage of this model will involve emission prediction of other types of alternative jet fuel at various blending with Jet A as well as consideration of its economic impact [16]. Overall, this paper helps to establish the emission prediction model for a multidisciplinary assessment framework for a thorough evaluation of alternative fuel usage in aviation.

\section{Acknowledgment}

The authors would like to acknowledge the financial support of this paper from Univ. Tun Hussein Onn Malaysia.

\section{References}

[1] A. Koch, B. Nagel, V. Gollnick, K. Dahlmann, V. Grewe, B. Kärcher, and U. Schumann, "Integrated analysis and design environment for a climate compatible air transport system," in 9th AIAA Aviation Technology, Integration, and Operations Conference, 2009.

[2] Boeing, "Current Market Outlook 2013 - 2032," 2013.

[3] IATA, "A Global Approach to Reducing Aviation Emissions," Switzerland, 2009.

[4] N. Chandrasekaran and A. Guha, "Development and optimization of a sustainable turbofan aeroengine for improved performance and emissions," Proc. Inst. Mech. Eng. Part G J. Aerosp. Eng., vol. 227, no. 11, pp. 1701-1719, Oct. 2012.

[5] R. W. Stratton, H. M. Wong, and J. I. Hileman, "The Potential of Low Carbon Drop - In Alternative Fuels," pp. 1-6, 2011.

[6] J. D. Kinder, "Evaluation of Bio-Derived Synthetic Paraffinic Kerosenes (Bio-SPKs)," 2010.

[7] N. Chandrasekaran and A. Guha, "Study of Prediction Methods for NOx Emission from Turbofan Engines," J. Propuls. Power, vol. 28, no. 1, pp. 170-180, Jan. 2012.

[8] D. Dubois and G. C. Paynter, "Fuel Flow Method 2 for Estimating Aircraft Emissions," no. 724. SAE International, Warrendale, PA, 2006.

[9] B. Kim and J. Rachami, "Aircraft Emissions Modeling Under Low Power Conditions," Observatory of Sustainability in Aviation, 2008.

[10] B. Sridhar, N. Chen, H. Ng, and A. Morando, "Modeling and Simulation of the Impact of Air Traffic Operations on the Environment," AIAA Model. Simul. Technol. Conf., pp. 1-12, Aug. 2011.

[11] J. T. Wilkerson, M. Z. Jacobson, A. Malwitz, S. Balasubramanian, R. Wayson, G. Fleming, A. D. Naiman, and S. K. Lele, "Analysis of emission data from global commercial aviation: 2004 and 2006," Atmos. Chem. Phys., vol. 10, no. 13, pp. 6391-6408, Jul. 2010.

[12] S. N. M. Mohd Yunos, M. F. Abdul Ghafir, and M. S. Zamri, "The Impact of Altitude, Mach Number And Relative Humidity Towards Aircraft Engine Emission,” Aust. J. Basic Appl. Sci., vol. 8, no. 24, pp. 367-374, 2014.

[13] P. A. Bonnefoy, G. Burdette, T. Carroll, J. Hansman, J. Hileman, S. Isley, M. Kirby, D. Lim, D. Mavris, A. Mozdzanowska, T. Nam, S. Smith, R. Taylor, I. A. Waitz, R. Willett, J. S. Wilson, and B. Yutko, "Assessment of $\mathrm{CO} 2$ Emission Metrics for a Commercial Aircraft Certification Requirement," Cambridge, MA, 2011.

[14] ICAO, "EASA - ICAO Aircraft Engine Emissions Databank," 2014. [Online]. Available: http://easa.europa.eu/node/15672.

[15] E. T. Turgut, O. Usanmaz, and M. a Rosen, "Empirical model assessment of commercial aircraft emissions according to flight phases," Int. J. Energy Environ. Eng., vol. 4, no. 1, 2013.

[16] S. N. M. Mohd Yunos, M. F. Abdul Ghafir, and A. Ab Wahab, "An Evaluation of Economic Model for Assessing Aviation Environmental Impacts towards Airline Operations," in Applied Mechanics and Materials, 2014, vol. 629, pp. 338-343. 